\title{
A Scanning Electron Microscopic Observation of Detached Dental Calculus on Cementum Surface
}

\author{
by \\ Yoshihisa TODA, Masato KAGEYAMA, Kohichi TOHNAI, Akira ICHINOSE, \\ Takahisa KASAMO, Akira ITO, Hidehito KADO, Yutaka MAEDA, \\ Yasuchika MURAKAMI and Haruji SUGISAWA
}

\section{Introduction}

Dental calculus formed on the cervical portion of the tooth is known to result from the calcification of dental plaque.

In this study the authors selected dental calculus formed on the surface of cementum, observed the detached surfaces of both the calculus and the cementum using scanning electron microscopy and obtained some interesting results.

\section{Materials and Methods}

The authors used twelve extracted teeth which had been diagnosed as having chronic marginal periodontitis and had had calculus adhering to their cementum. After the extraction of these teeth the calculus that had adhered to the cementum was carefully removed using a scaler. The calculus was then trimmed on both detached surfaces to form squares, roughly 3 by $3 \mathrm{~mm}$. The materials thus obtained were fixed with a $1 \%$ glutaraldehyde solution buffered with $0.5 \mathrm{M}$ sodium cacodylate ( $\mathrm{pH} 7.3$ ) for 24 hours. Some of the materials were soaked in $10 \%$ sodium hypochlorite for 24 hours at $60^{\circ} \mathrm{C}$ for the purpose of removing the organic substances contained in the calculus. These materials were dehydrated with ethyl alcohol and immersed in amylacetate. They were then dried using the critical point drying method. Ion sputter coating with gold paradium was given to the surface of the materials. Observations were made of these materials with an HFS-2S scanning electron microscope.

The authors also used two upper second premolars which had been extracted for orthodontic therapy and observed surface and cross sections of the cementum by the above-mentioned method in an attempt to study the properties of the calculus on the surface of the cementum.

\section{Results}

Most of the surface of the cementum, from which the calculus had been detached, showed thick clusters of semi-spherical structures about 5-8 $\mu$ in diameter. Cocci and rods were found attached to their surfaces (Fig. 1). The dental calculus, however, showed spongy-like, plate-like and leaflet-like structures. In the material

戸田善久, 景山正登, 東内公一, 一瀬 明, 笠茂享久, 伊藤 昭, 角 秀人, 前田 豊, 村上康親, 杉沢治二: Department of Anatomy, Nihon University School of Dentistry. 


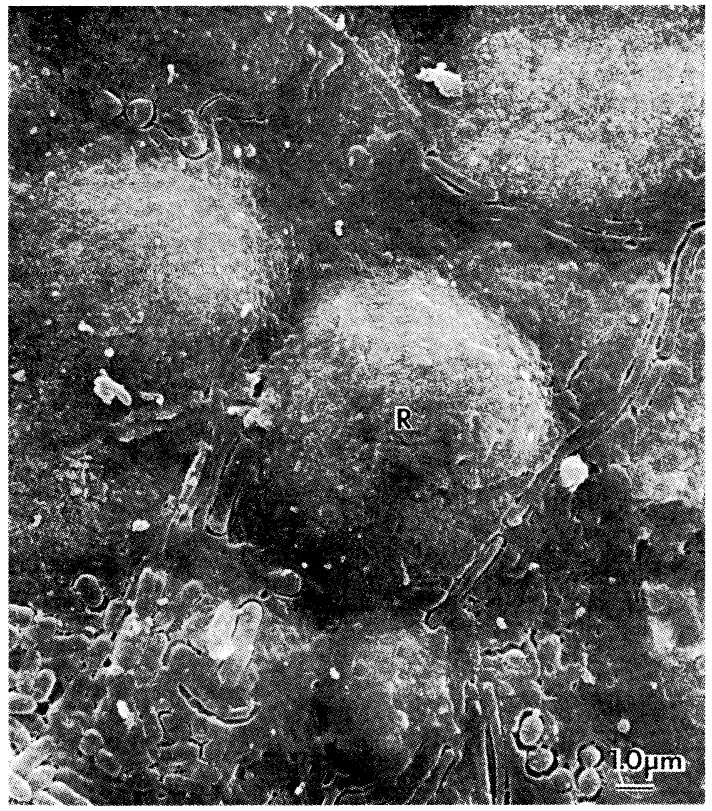

Fig. 1 Cocci and rods were found attached to cementum surface $\mathrm{R}$ : semi-spherical structure

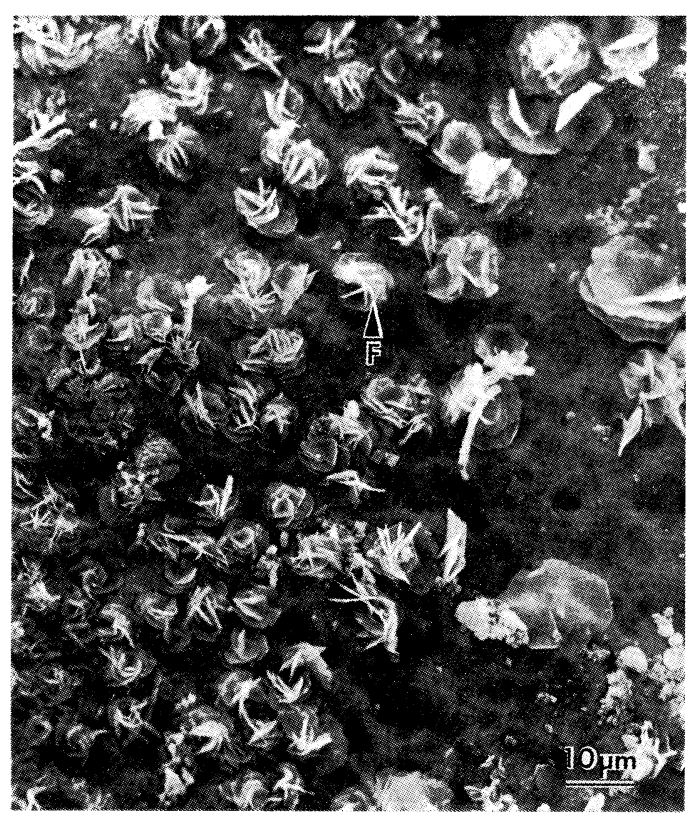

Fig. 2 Leaflet-like calculus on cementum surface F: petal-like structure 


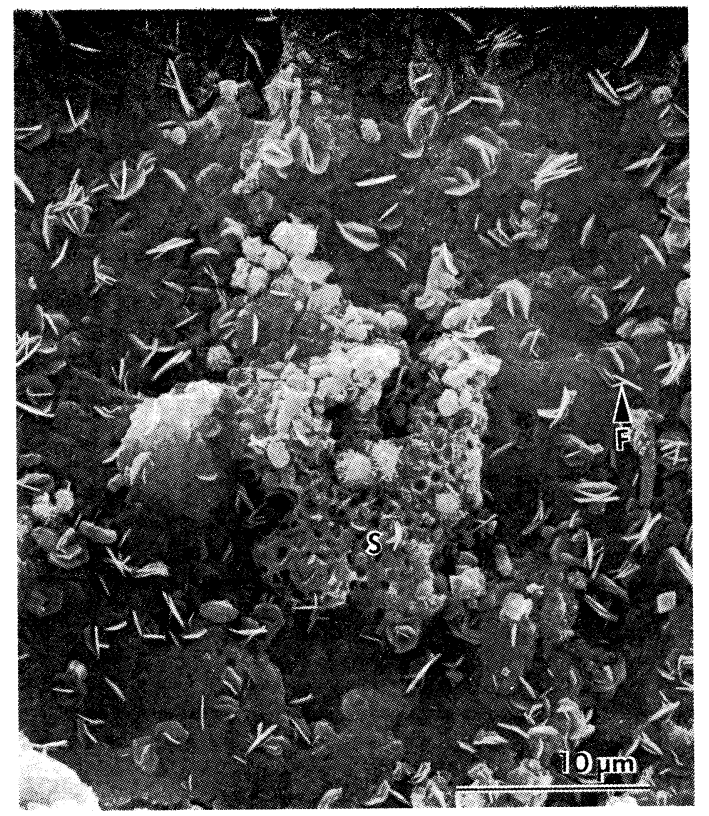

Fig. 3 Detached surface of calculus

$\mathrm{S}$ : spongy-like calculus

F: petal-like structure

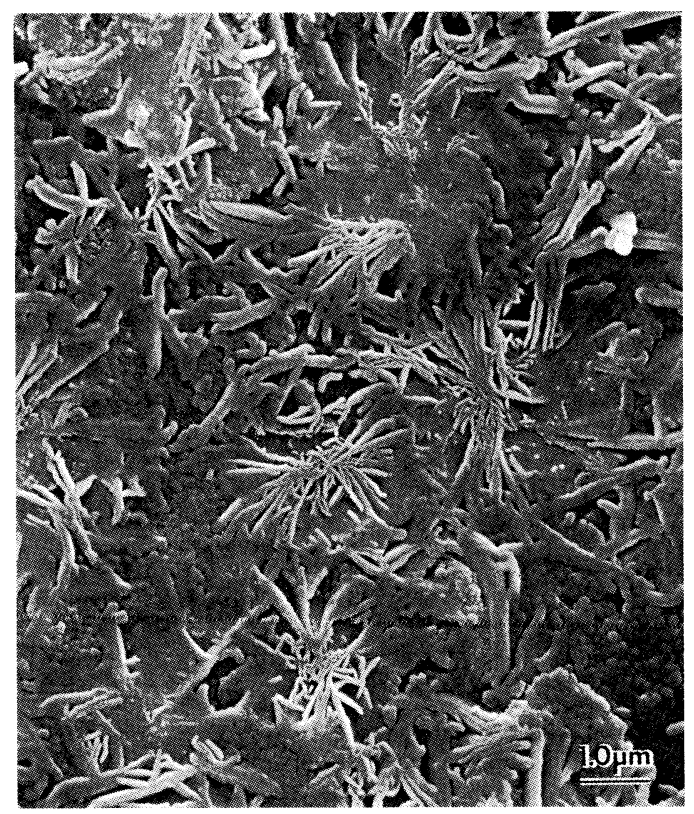

Fig. 4 Surface of cementum with organic substances removed 


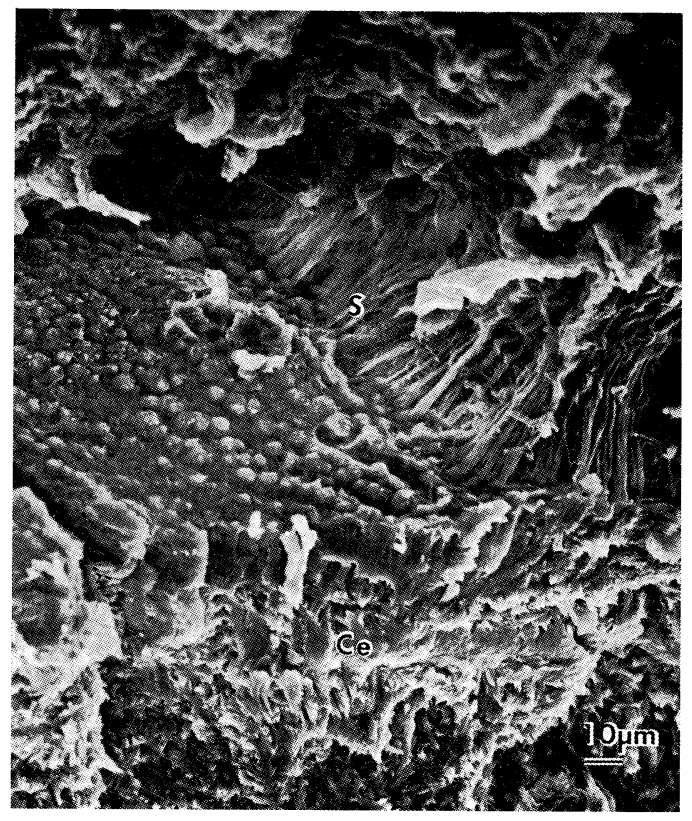

Fig. 5 Surface of cementum S: Sharpey's fibers Ce: cementum

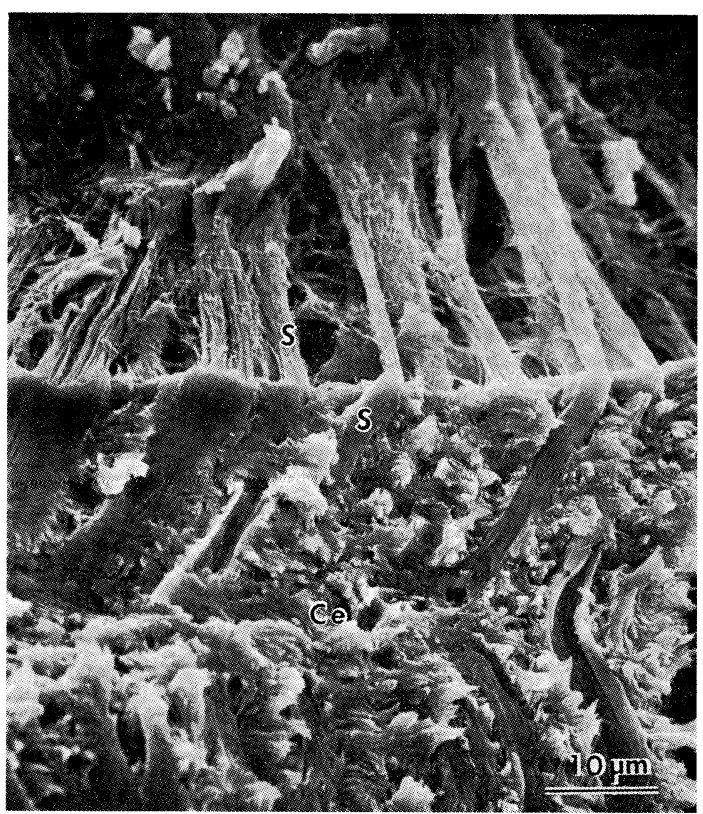

Fig. 6 Cross section of cementum S: Sharpey's fibers

Ce: cementum 
from which the organic substances had been removed, depressions 5-9 $\mu$ in size were present on the surface of the cementum to which the calculus had adhered. In each of the depressions was found dental calculus about 4-5 $\mu$ in diameter, a mass of leaflet-like structures that had the appearance of the petals of a flower (Fig. 2). On the detached surface of the calculus as well was found calculus of identical shape (Fig. 3).

Also observed on the surface of the cementum from which the organic substances had been removed was calculus suggestive of a crushed bundle of Sharpey's fibers (Fig. 4).

The surface of the cementum of the tooth extracted for orthodontic therapy showed stubble-like structures about 4-6 $\mu$ in diameter where Sharpey's fibers had been cut off (Fig. 5). A cross section of the cementum shows that Sharpey's fibers, having entered the cementum, are shooting out of its surface in bundles (Fig. 6).

\section{Discussion and Conclusions}

It is generally said that calculus which results from the calcification of plaque is classified, according to X-ray diffraction[1], into four types: hydroxyapatite, octacalcium phosphate, brushite and whitlockite. SHroeder[1] had classed dental calculus into two types: A and B-types. Dental calculus formed by bacteria belongs to the former, whereas calculus formed without the direct involvement of bacteria belongs to the latter. SATO[2] has divided calculus into four kinds by using scanning electron microscopy.

The observations of the cementum to which dental calculus had adhered and of the detached surface of the calculus brought some interesting images that might suggest a relationship between dental calculus and Sharpey's fibers. Semi-spherical structures 5-8 $\mu$ in diameter were observed on the detached surface of the cementum from which the calculus had been removed (Fig. 1). These structures were slightly bigger in size than the cut-off ends of Sharpey's fibers on the surface of the cementum (Fig. 5). Calcified bacteria observde on the semi-spherical surface might be responsible for the difference in size, thus suggesting a relationship between the two.

Leaflet-like structures of calculus which were similar in shape and 5-9 $\mu$ in diameter were observed on the detached surfaces of both the cementum and the calculus. Their size also suggests a relationship with Sharpey's fibers.

Calculus that looked like a crushed bundle of Sharpey's fibers was observed on the surface of the cementum (Fig. 4). This may be related to the bundles of Sharpey's fibers that are shooting out of the surface of the cementum (Fig. 6). Thus, implications are that in addition to A- and B-type calculus, calculus related to collagen fibrils may be present on the surface of the cementum.

\section{References}

[1] Schroeder, H. E. 1969. Formation and Inhibition of dental calculus, pp. 94-122, Hans Huber, Berne.

[2] SAto, K. 1981. Scanning Electron Microscopic Observations of Dental Plaque and Calculus, Nihon Univ. Dent. J., 55, 190-198 (in Japanese). 